MATHEMATICS OF COMPUTATION

Volume 73, Number 245, Pages 475-491

S 0025-5718(03)01554-0

Article electronically published on June 19, 2003

\title{
ALL NUMBERS WHOSE POSITIVE DIVISORS HAVE INTEGRAL HARMONIC MEAN UP TO 300
}

\author{
T. GOTO AND S. SHIBATA
}

\begin{abstract}
A positive integer $n$ is said to be harmonic when the harmonic mean $H(n)$ of its positive divisors is an integer. Ore proved that every perfect number is harmonic. No nontrivial odd harmonic numbers are known. In this article, the list of all harmonic numbers $n$ with $H(n) \leq 300$ is given. In particular, such harmonic numbers are all even except 1.
\end{abstract}

\section{INTRODUCTION}

A positive integer $n$ is said to be perfect if $\sigma(n)=2 n$, where $\sigma(n)$ denotes the sum of the positive divisors of $n$. It is an open problem whether or not an odd perfect number exists. In this connection, Ore [8] introduced the concept of harmonic numbers. A positive integer $n$ is said to be harmonic if the harmonic mean of its positive divisors

$$
H(n)=\frac{n \tau(n)}{\sigma(n)}
$$

is an integer, where $\tau(n)$ denotes the number of the positive divisors of $n$. Ore proved the following fact which represents the relationship between perfect numbers and harmonic numbers.

Theorem 1.1 ([8]). Every perfect number is harmonic.

The converse of this theorem does not hold. For example, 140 is not perfect, but $H(140)=5$. Ore listed all harmonic numbers up to $10^{4}$ and this list was extended by Garcia $\left[5\right.$ to $10^{7}$ and by Cohen 2$]$ to $2 \cdot 10^{9}$. No nontrivial odd harmonic numbers have been discovered. Ore conjectured the following statement. If this conjecture holds, it follows that odd perfect numbers do not exist.

Conjecture. All harmonic numbers other than 1 must be even.

Kanold [7] showed the following fact.

Theorem 1.2 (7]). For any positive integer $c$, there exist only finitely many numbers $n$ satisfying $H(n)=c$.

In [6, B2], Guy wrote: "Which values does the harmonic mean take? Presumably not $4,12,16,18,20,22, \ldots$; does it take the value 23?" Cohen [2] settled the first of these questions for the first two values.

Received by the editor December 10, 2001 and, in revised form, July 17, 2002.

2000 Mathematics Subject Classification. Primary 11A25, 11Y70.

Key words and phrases. Harmonic number, perfect number, Ore's conjecture.

(C)2003 American Mathematical Society 
Theorem $1.3(2])$. Let $n$ be harmonic and $H(n) \leq 13$. Then $n$ is one of the 13 numbers listed in Table 4 (at the end of this paper). In particular, the numbers $n$ with $H(n)=4$ or 12 do not exist.

This result is extended to $H(n) \leq 300$. For this, some propositions and a computer were used. The program is written by Mathematica ${ }^{\circledR}$, and it takes about three months to get the result. For $H(n) \leq 200$, we need only about two days.

Main result. Let $n$ be harmonic and $H(n) \leq 300$. Then $n$ is one of the 280 numbers listed in Table 4 (at the end of this paper). In particular, such harmonic numbers are all even except 1 . The table includes the nonexistence of numbers $n$ with $H(n)$ being equal to one of the numbers that Guy listed. In the table, the values of $H(n) \leq 300$ are omitted when there is no corresponding value of $n$.

For example, we solve the equation $H(n)=14$ in $\S 5$. In $\S 2$, we recall the known facts about harmonic numbers. Then the general method of the search for the harmonic numbers $n$ with $H(n)=c$ is explained in $\S 3$. In this search, the following proposition proved in $\S 4$ is useful.

Proposition 1.4. Let $p$ be prime. If $H(n)=2 p$, then $2 p \mid n$. If $H(n)=3 p$, then $p \mid n$.

This is analogous to the following fact due to Cohen.

Proposition $1.5([2])$. Let $p$ be prime. If $H(n)=p$, then either $p \mid n$ or $n$ is an even perfect number.

Cohen and Sorli [3] introduced the concept of harmonic seeds.

Definition. Let $d$ be a divisor of an integer $n$. We call $d$ a unitary divisor of $n$ and $n$ a unitary multiple of $d$ if $(d, n / d)=1$. A harmonic number is called a harmonic seed if it does not have a smaller proper unitary divisor which is harmonic (we call a unitary divisor $d$ proper if $d>1$ ).

Every harmonic number is a unitary multiple of a certain harmonic seed. It is conjectured that such a harmonic seed is unique. Table 4 includes the harmonic seed of all harmonic numbers listed, and in all of these cases the seed is unique.

\section{KNOWN FACTS}

In this section, we recall the known facts about harmonic numbers. The following lemma is a fundamental property of $H$, and we often use it without special mention.

Lemma 2.1. Let $n, m, e, f$ be positive integers and $p, q$ primes.

- $H$ is multiplicative, i.e., $H(n m)=H(n) H(m)$ if $(n, m)=1$.

- $H$ is monotone, i.e., $H\left(p^{e}\right)<H\left(p^{f}\right)<H\left(q^{f}\right)$ if $e<f$ and $p<q$.

Proof. The first statement is clear from the definition (11). The second statement is also clear from the fact that $H$ is averaging of positive numbers (this statement is a special case of Lemma 7 in Cohen and Deng [4]).

We denote the number of the distinct primes dividing $n$ by $\omega(n)$.

Theorem 2.2 ([8], [10]). Let $n$ be a harmonic number and $\omega(n) \leq 2$. Then $n$ is an even perfect number. 
Ore [8] proved the nonexistence of harmonic numbers $n$ with $\omega(n)=1$. In 1973, Pomerance proved that a harmonic number $n$ with $\omega(n)=2$ must be an even perfect number (cf. [10]), and Callan [1] rediscovered the proof of the same fact in 1992.

Theorem $2.3([8])$. Let $n$ be a harmonic number greater than 6 . Then $n$ is not squarefree.

Theorem $2.4([3])$. For any integer $n$,

$$
H(n)>\frac{2^{\omega(n)+1}}{\omega(n)+1},
$$

with the following exceptions (in which $p$ denotes a prime): $n=p, n=2 p, n=6 p$ $(p \neq 3), n=30 p(7 \leq p \leq 23), n=1,15,21,70$. By Theorems 2.2 and 2.3, $a$ harmonic number $n$ greater than 6 satisfies the inequality.

Theorem 2.5 ([5]). Let $n$ be an odd harmonic number and $p^{e} \| n$. Then $p^{e} \equiv 1$ $(\bmod 4)$.

In order to prove Theorem 2.5, we provide the following lemma, which is often used later. Let $p$ be a prime and let $Q$ be a rational number. Suppose that $Q=p^{e} m / n$ with $p \nmid m n$. Then we denote by $\operatorname{ord}_{p}(Q)$ the exponent $e$ in this paper.

Lemma 2.6. Let $p$ be an integer (not necessarily prime). If $p \equiv 1(\bmod 4)$, then

$$
\operatorname{ord}_{2}\left(1+p+\cdots+p^{e}\right)=\operatorname{ord}_{2}(e+1) .
$$

If $p \equiv 3(\bmod 4)$ and $\operatorname{ord}_{2}(p+1)=m$, then

$$
\operatorname{ord}_{2}\left(1+p+\cdots+p^{e}\right)= \begin{cases}\operatorname{ord}_{2}(e+1)+m-1, & \text { if } e \text { is odd, } \\ 0, & \text { if } e \text { is even } .\end{cases}
$$

Proof of Theorem 2.5. Let $p$ be a prime and $e$ a positive integer. If $p^{e} \equiv 1(\bmod 4)$. Then $\operatorname{ord}_{2}\left(H\left(p^{e}\right)\right)=0$ by Lemma 2.6. If $p^{e} \equiv 3(\bmod 4)$, then $\operatorname{ord}_{2}\left(H\left(p^{e}\right)\right)<0$. Hence $H(n)$ cannot be integral if $p^{e} \equiv 3(\bmod 4), p^{e} \| n$ and $2 \nmid n$.

Lemma 2.6 is a standard fact. For example, see [9]. The following simple proof is due to Koichi Tanaka, an undergraduate student of Kyushu University.

Proof of Lemma[2.6. Let $e+1=2^{k} l$, where $k$ is an integer and $l$ is odd. The statement is clear when $k=0$. Suppose that $k \geq 1$. Then

$$
\begin{aligned}
1+p+\cdots+p^{e} & =\left(p^{e+1}-1\right) /(p-1)=\left({p^{2} l}^{k}-1\right) /(p-1) \\
& =\left(p^{2^{(k-1)} l}+1\right)\left(p^{2^{(k-2)} l}+1\right) \cdots\left(p^{2 l}+1\right)\left(p^{l}+1\right)\left(p^{l}-1\right) /(p-1) .
\end{aligned}
$$

The last part of this expression $\left(p^{l}-1\right) /(p-1)=p^{l-1}+\cdots+p+1$ is odd, and the rest of the parts are all even. In particular, $p^{2^{(k-i)} l}+1 \equiv 2(\bmod 4)$ for $1 \leq i \leq k-1$. Since $p^{l}+1=(p+1)\left(p^{l-1}-\cdots+1\right)$,

$$
\operatorname{ord}_{2}\left(p^{l}+1\right)=\operatorname{ord}_{2}(p+1)= \begin{cases}1, & \text { if } p \equiv 1(\bmod 4) \\ m, & \text { if } p \equiv 3(\bmod 4) .\end{cases}
$$

Now, the proof is complete. 


\section{General Algorithm}

In this section, we give the general algorithm of searching all integers $n$ satisfying $H(n)=c$ for a fixed integer $c$. Roughly speaking, it has three steps.

(1) List the possibilities of $\omega(n)$, the number of distinct primes dividing $n$.

(2) For each value of $\omega(n)$, list the possibilities of the types of exponents in the factorization of $n$.

(3) For each type of exponents, list the possibilities of primes dividing $n$.

Then check whether or not $H(n)=c$ for the finite possibilities of $n$. Practically, the existence of this algorithm verifies Theorem 1.2

This algorithm finishes in finite time, but not always in reasonable time. We can make this time shorter, using Propositions 1.4 and 1.5, Lemma 4.1, and some methods explained in $\S 5$.

3.1. Possibilities of the numbers of distinct primes. Recall that we denote the number of distinct primes dividing $n$ by $\omega(n)$. Suppose that $n$ is harmonic. Then either $n$ is an even perfect number or $\omega(n) \geq 3$ by Theorem 2.2 And Theorem 2.4 gives an upper bound of $\omega(n)$. But in order to get the upper bound, we may use the following method.

For example, suppose that $\omega(n)=5$. Then $H(n) \geq H(2 \cdot 3 \cdot 5 \cdot 7 \cdot 11)$. For harmonic number $n, H(n) \geq H\left(2^{2} \cdot 3 \cdot 5 \cdot 7 \cdot 11\right)=13.75$ because such $n$ must not be squarefree by Theorem 2.3 (see also Lemma 4.2). Since $H(n)$ is integral, we have $H(n) \geq 14$. Thus, we get Table 1

Note that Cohen 2] gives a more precise version of such a table.

Example. Suppose that $H(n)=5$. Then $\omega(n)$ must be 2 or 3 . Next, suppose that $H(n)=14$. Then $n$ cannot be an even perfect number, so $\omega(n)$ must be 3,4 or 5 .

3.2. Possibilities of the types of exponents. We denote by $\left(e_{1}, \ldots, e_{r}\right)$ the type of exponents of $n=p_{1}^{e_{1}} \cdots p_{r}^{e_{r}}$ with $e_{1} \geq \cdots \geq e_{r}$. Suppose a harmonic number $n$ has the type $\left(e_{1}, \ldots, e_{r}\right)$. Since $H\left(p^{e}\right)<e+1$, we have $H(n) \leq\left(e_{1}+1\right) \cdots\left(e_{r}+1\right)-1$. We can take the round-up of the value $H\left(2^{e_{1}} \cdot 3^{e_{2}} \cdots q_{r}^{e_{r}}\right)$ as the lower bound of $H(n)$, where $q_{r}$ is the $r$ th prime.

Example. Suppose that $H(n)=5$ and $n$ is not an even perfect number. Then $\omega(n)$ must be 3 . The type of exponents is not $(1,1,1)$ by Theorem $[2.3$. When it is $(2,1,1)$, the lower bound of $H$ is 5 since $H\left(2^{2} \cdot 3 \cdot 5\right)=4.28 \cdots$. The upper bound is $3 \cdot 2 \cdot 2-1=11$. If the type is $(2,2,1)$ or $(3,1,1)$, then $H(n) \geq 6$. Hence the only possibility of the type of exponents is $(2,1,1)$.

TABLE 1. The lower bound of integral $H(n)$

\begin{tabular}{|r|r|r|}
\hline$\omega(n)$ & Theorem 2.4 & this method \\
\hline 3 & 4 & 5 \\
4 & 7 & 8 \\
5 & 11 & 14 \\
6 & 19 & 26 \\
7 & 32 & 49 \\
8 & 57 & 92 \\
9 & 103 & 176 \\
10 & 187 & 340 \\
\hline
\end{tabular}


Cohen and Deng [4] have already given the inequality $H(n) \leq \tau(n)-1$ for harmonic numbers $n$. Using Theorem 1.3 they also showed $H(n) \leq \tau(n)-8$ when $n$ is an even harmonic number and $n \neq 6,28,140,496,8128$. An improved result is possible using the main result of this paper.

3.3. Possibilities of primes. We define $S(n)=\sigma(n) / n$. Let $p, q$ be primes and $e, f$ positive integers. If $p<q$ and $e<f$, then it is easily verified that

$$
1<S\left(q^{e}\right)<S\left(q^{f}\right)<S\left(p^{e}\right)<S\left(p^{f}\right)<2
$$

and $S\left(p^{e}\right) \rightarrow p /(p-1)$ as $e \rightarrow \infty$. Suppose that the type of exponents of $n$ is $\left(e_{1}, \ldots, e_{r}\right)$. Then $\tau(n)=\left(e_{1}+1\right) \cdots\left(e_{r}+1\right)$. Since $H(n)=c$, which is fixed, $S(n)$ must be equal to $\tau(n) / H(n)=\left(e_{1}+1\right) \cdots\left(e_{r}+1\right) / c$. If the smallest prime dividing $n$ is $p$, then $S(n)<S\left(p^{e_{1}}\right) \cdots S\left(p^{e_{r}}\right)<(p /(p-1))^{r}$, so it follows that $p<S(n)^{1 / r} \cdot\left(S(n)^{1 / r}-1\right)^{-1}$. In this way, we have the finite possibilities of the second smallest prime dividing $n$, third smallest prime, and so on.

Example. Suppose that $H(n)=5$ and $n$ is not an even perfect number. Then the type of the exponents of $n$ must be $(2,1,1)$. So we have $\tau(n)=3 \cdot 2 \cdot 2=12$ and $S(n)=\tau(n) / H(n)=12 / 5$. If $n$ were odd, then $S(n) \leq S\left(3^{2} \cdot 5 \cdot 7\right)=208 / 105<$ $12 / 5$, a contradiction. Therefore it follows that $2 \mid n$. Next, if the second smallest prime dividing $n$ were greater than 5 , then $S(n) \leq S\left(2^{2} \cdot 7 \cdot 11\right)=24 / 11<12 / 5$, a contradiction. Therefore it follows that the second smallest prime dividing $n$ is 3 or 5. By Proposition 1.5, we have $5 \mid n$. If $3 \mid n$, then the possibilities of $n$ are $2^{2} \cdot 3 \cdot 5$, $2 \cdot 3^{2} \cdot 5$ and $2 \cdot 3 \cdot 5^{2}$, but $H(n)$ is not integral in these cases. Let $p$ be a prime greater than 5 . If $n=2^{2} \cdot 5 \cdot p$, then $H(p)=5 / H\left(2^{2} \cdot 5\right)=7 / 4$, so $p=7$. We get a solution $n=2^{2} \cdot 5 \cdot 7=140$. If $n=2 \cdot 5^{2} \cdot p$, then $H(p)=5 / H\left(2 \cdot 5^{2}\right)=31 / 20$, but this does not have a solution. Similarly, there does not exist a solution in the case that $n=2 \cdot 5 \cdot p^{2}$. Hence all the solutions of $H(n)=5$ are 140 and an even perfect number 496. We remark that Cohen and Sorli [3] have given a simpler proof of this fact, but their proof is not as algorithmically viable.

\section{Proof of Proposition 1.4}

In this section, we give the proof of Proposition 1.4

Lemma 4.1. If $H(n)$ is even, then $n$ is even.

Proof. Let $p$ be an odd prime and $e$ a positive integer. Then $\operatorname{ord}_{2}\left(H\left(p^{e}\right)\right) \leq 0$ by Lemma 2.6. Hence $H(n)$ cannot be even for an odd integer $n$.

The following lemma is a special case of Lemma 5 in Cohen and Deng [4].

Lemma 4.2. Let $e, f$ be nonnegative integers and $p, q$ primes. If $e<f$ and $p<q$, then $H\left(p^{e} q^{f}\right)>H\left(p^{f} q^{e}\right)$.

Proof of Proposition 1.4. We give only the proof of the first statement. The second statement can be proved similarly. Let $H(n)=2 p$. In view of Lemma 4.1] it is sufficient to show that $p \mid n$. Assume that $p \nmid n$. Then $p \mid \tau(n)$ since $n \tau(n)=$ $2 p \sigma(n)$. We put $n=q^{k p-1} m$ with a prime $q$ and positive integers $k$ and $m$. We can assume without loss of generality that $q \nmid m$. Since $\omega(n) \geq 3$ by Theorem 2.2 it follows that $\omega(m) \geq 2$. So we have $H(n)=H\left(q^{k p-1} m\right) \geq H\left(2^{k p-1}\right) H(6)>k p$. Hence $k=1$ and $n=q^{p-1} m$. Since

$$
\frac{q-1}{q} p<H\left(q^{p-1}\right)<p
$$


and $H(n)=2 p$, we have

Therefore it follows that

$$
2<H(m)<\frac{2 q}{q-1}
$$

$$
\frac{20}{9}=H(10)<\frac{2 q}{q-1}
$$

so the possibilities of $q$ are only $2,3,5$ and 7 .

(i) Assume that $n=7^{p-1} m$ with $7 \nmid m$. Since $6 p / 7<H\left(7^{p-1}\right)<p$, we have $2<H(m)<7 / 3$. Therefore the only possibility of $m$ is 10 . From the equation $H\left(7^{p-1} \cdot 10\right)=2 p$, we have $7^{p-1}=3$, a contradiction.

(ii) Assume that $n=5^{p-1} m$ with $5 \nmid m$. Since $4 p / 5<H\left(5^{p-1}\right)<p$, we have $2<H(m)<5 / 2$. But we give a better estimation below. When $p=2,3,5$, the statement holds by Theorem 1.3. From now on, we assume that $p \geq 7$. Then it follows that

$$
H\left(5^{p-1}\right)=\frac{4 \cdot 5^{p-1} p}{5^{p}-1} \leq \frac{4 \cdot 5^{6}}{5^{7}-1} p .
$$

Hence $H(m) \geq\left(5^{7}-1\right) /\left(2 \cdot 5^{6}\right)>2.4999$.

Claim. There does not exist an integer $m$ satisfying $2.4999<H(m)<2.5$.

Suppose that $2.4999<H(m)<2.5$. If $\omega(m) \geq 3$, then $H(m) \geq H(2 \cdot 3 \cdot 5)>2.5$. So we have $\omega(m) \leq 2$.

Assume that $\omega(m)=2$ and let $m=p^{e} q^{f}$ be the factorization of $m$. If $\max (e, f) \geq$ 2, then $H(m) \geq H\left(2^{2} \cdot 3\right)>2.5$ by Lemmas 2.1 and 4.2 So we have $f=e=1$. If $m$ is odd, then $H(m) \geq H(3 \cdot 5)=2.5$, a contradiction. Assume that $m$ is even. Since $H(2 \cdot 13)=2.47 \cdots$ and $H(2 \cdot 17)=2.51 \cdots$, it is impossible that $2.4999<H(m)<2.5$. Similarly, we can deal with the case that $\omega(m)=1$.

(iii) We can deal with the case $n=3^{p-1} m$ with $3 \nmid m$ similarly. In fact, there does not exist an integer $m$ satisfying $2.998<H(m)<3, \omega(m) \geq 2$ and $3 \nmid m$.

(iv) Assume that $n=2^{p-1} m$ with $2 \nmid m$. Since

$$
\frac{1}{2} p<H\left(2^{p-1}\right)=\frac{2^{p-1} p}{2^{p}-1} \leq \frac{2^{6}}{2^{7}-1} p
$$

we have $3.96875<H(m)<4$. Such integers $m$ satisfying $\omega(m) \geq 2$ and $2 \nmid m$ are only $3^{2} \cdot 23$ and products of distinct two odd primes. First, put $H\left(2^{p-1} 3^{2} \cdot 23\right)=2 p$. Then we have $2^{p-1}=104$, a contradiction.

Next, put $H\left(2^{p-1} p_{1} p_{2}\right)=2 p$, where $p_{1}$ and $p_{2}$ are distinct odd primes. Then it follows that

Therefore we have

$$
\frac{2^{p-1} p}{2^{p}-1} \cdot \frac{p_{1}}{\frac{p_{1}+1}{2}} \cdot \frac{p_{2}}{\frac{p_{2}+1}{2}}=2 p
$$

$$
2^{p-2} p_{1} p_{2}=\left(2^{p}-1\right) \cdot \frac{p_{1}+1}{2} \cdot \frac{p_{2}+1}{2} .
$$

Hence the odd integer $2^{p}-1$ is equal to either one of $p_{1}, p_{2}$ or the product $p_{1} p_{2}$.

If $2^{p}-1=p_{1}$, then

$$
2^{p-2} p_{2}=\frac{p_{1}+1}{2} \cdot \frac{p_{2}+1}{2}=2^{p-1} \cdot \frac{p_{2}+1}{2},
$$

which has no solution. If $2^{p}-1=p_{1} p_{2}$, then

$$
2^{p-2}=\frac{p_{1}+1}{2} \cdot \frac{p_{2}+1}{2} .
$$


Hence we have $p_{1} p_{2}+1=\left(p_{1}+1\right)\left(p_{2}+1\right)$, a contradiction. Now, all the possibilities of $p \nmid n$ are denied, so the proof is complete.

\section{ONLY SOlution OF $H(n)=14$}

In this section, we show that $n=18620$ is the only solution of $H(n)=14$ using Proposition 1.4. For such an integer $n$, it follows that $\omega(n) \geq 3$ and $14 \mid n$ by Theorem 2.2 and Proposition 1.4 Let

$$
\operatorname{ord}_{2}(n)=s, \quad \operatorname{ord}_{7}(n)=t .
$$

We have $1 \leq s \leq 9$ since $H\left(2^{10} \cdot 7 \cdot 3\right)>14$. Similarly we have $1 \leq t \leq 7$. Table 2 is the table of $H\left(2^{s}\right)$.

Suppose that $s=9$ and $n=2^{9} \cdot 7^{t} m$ with $(m, 14)=1$. Since $H(n)$ is an integer, it is necessary that $31 \mid \tau(n)$ or $31 \mid m$. Assume that $31 \mid \tau(n)$. Then $n$ has a prime raised to 30th power or higher as a factor. In this case, $H(n)>H\left(2^{9} \cdot 3^{30}\right)>14$, a contradiction. In the case that $31 \mid m$, we also have $H(n) \geq H\left(2^{9} \cdot 7 \cdot 31\right)>14$. In this way, the possibilities of $s=7,8,9$ are denied.

In the case that $s=6$, it is necessary that $127 \mid n$. We put $n=2^{6} \cdot 127^{u} m$, where $u$ is a positive integer and $(m, 254)=1$. If $u$ is odd, then $\operatorname{ord}_{2}(H(n)) \leq 0$ by Lemma 2.6 hence it is impossible that $H(n)=14$. If $u$ is even, then $H(n) \geq$ $H\left(2^{6} \cdot 127^{2} \cdot 3\right)>14$. A similar argument denies the possibility of $s=4$. Put $n=2^{4} \cdot 31^{u} m$ with $(m, 62)=1$. Then $u$ must be even and it is necessary that $\operatorname{ord}_{2}(H(m))=-3$ by Lemma [2.6. But $H(n) \geq H\left(2^{4} \cdot 31^{2} \cdot 47\right)>14$ in this case.

From now on, the following clear fact is often used.

Lemma 5.1. Let $m$ be a positive integer. The smallest values of $H(m)$ are as follows:

$$
H(1)=1, H(2)=4 / 3=1.33 \cdots, H(3)=3 / 2=1.5, H(5)=5 / 3=1.66 \cdots .
$$

In other cases, $H(m)>1.7$.

Suppose that $s=5$ and $n=2^{5} \cdot 7^{t} m$ with $(m, 14)=1$. If $t \geq 3$, then $H(n) \geq$ $H\left(2^{5} \cdot 7^{3}\right)>14$, a contradiction. Assume that $t=2$. Since $H\left(2^{5} \cdot 7^{2}\right)=\left(2^{6} \cdot 7\right) /(3 \cdot 19)$, it is necessary that $19 \mid n$. But $H(n) \geq H\left(2^{5} \cdot 7^{2} \cdot 19\right)>14$. Assume that $t=1$. Then $H(m)=14 / H\left(2^{5} \cdot 7\right)=1.31 \cdots$, a contradiction to Lemma 5.1 Therefore the possibility of $s=5$ is denied.

Next, we give Table 3, the table of $H\left(7^{t}\right)$.

The possibilities of $4 \leq t \leq 7$ are denied by an argument similar to that of the cases of $7 \leq s \leq 9$. Assume that $t=1$ and $n=7 m$ with $7 \nmid m$. Then $H(m)=H(n) / H(7)=8$. By Theorem 1.3, we have $m=2^{5} \cdot 3 \cdot 7$. But this is a contradiction to $7 \nmid m$. Hence $t=2$ or 3 . When $t=3$, it is necessary that $s=3$ since $\operatorname{ord}_{2}\left(H\left(7^{3}\right)\right)=-2$. The remaining possibilities are $s=3, t=2,3$, or $s=1,2$, $t=2$.

TABLE 2 .

\begin{tabular}{|c|c||c|c||c|c|}
\hline$s$ & $H\left(2^{s}\right)$ & $s$ & $H\left(2^{s}\right)$ & $s$ & $H\left(2^{s}\right)$ \\
\hline \hline 1 & $2^{2} / 3$ & 4 & $\left(2^{4} \cdot 5\right) / 31$ & 7 & $2^{10} /(3 \cdot 5 \cdot 17)$ \\
2 & $\left(2^{2} \cdot 3\right) / 7$ & 5 & $2^{6} /(3 \cdot 7)$ & 8 & $\left(2^{8} \cdot 3^{2}\right) /(7 \cdot 73)$ \\
3 & $2^{5} /(3 \cdot 5)$ & 6 & $\left(2^{6} \cdot 7\right) / 127$ & 9 & $\left(2^{10} \cdot 5\right) /(3 \cdot 11 \cdot 31)$ \\
\hline
\end{tabular}


TABLE 3 .

\begin{tabular}{|c|c||c|c||c|c|}
\hline$t$ & $H\left(7^{t}\right)$ & $t$ & $H\left(7^{t}\right)$ & $t$ & $H\left(7^{t}\right)$ \\
\hline \hline 1 & $7 / 2^{2}$ & 4 & $\left(5 \cdot 7^{4}\right) / 2801$ & 7 & $7^{7} /\left(2^{2} \cdot 5^{2} \cdot 1201\right)$ \\
2 & $7^{2} / 19$ & 5 & $7^{5} /\left(2^{2} \cdot 19 \cdot 43\right)$ & & \\
3 & $7^{3} /\left(2^{2} \cdot 5^{2}\right)$ & 6 & $7^{7} /(29 \cdot 4733)$ & & \\
\hline
\end{tabular}

Suppose that $s=3$ and $n=2^{3} \cdot 7^{t} m$, where $(m, 14)=1$ and $t=2$ or 3 . First, assume that $t=3$. Since $H\left(2^{3} \cdot 7^{3}\right)=\left(2^{3} \cdot 7^{3}\right) /\left(3 \cdot 5^{3}\right)$, it is necessary that $5 \mid n$. If $\operatorname{ord}_{5}(n) \geq 2$, then $H(n) \geq H\left(2^{3} \cdot 7^{3} \cdot 5^{2}\right)>14$. If $n=2^{3} \cdot 7^{3} \cdot 5 m$ with $(m, 70)=1$, then $H(m)=14 / H\left(2^{3} \cdot 7^{3} \cdot 5\right)=1.14 \cdots$, a contradiction to Lemma 5.1 Secondly, assume that $t=2$. Since $H\left(2^{3} \cdot 7^{2}\right)=\left(2^{5} \cdot 7^{2}\right) /(3 \cdot 5 \cdot 19)$, it is necessary that $19 \mid n$. But we deduce a contradiction by the above argument.

Suppose that $s=2$ and $t=2$. Since $H\left(2^{2} \cdot 7^{2}\right)=\left(2^{2} \cdot 3 \cdot 7\right) / 19$, it is necessary that $19 \mid n$. If $19^{3} \mid n$, then $H(n) \geq H\left(2^{2} \cdot 7^{2} \cdot 19^{3}\right)>14$. Assume that $19^{2} \| n$ and put $n=2^{2} \cdot 7^{2} \cdot 19^{2} m$ with $(m, 266)=1$. Then $H(m)=14 / H\left(2^{2} \cdot 7^{2} \cdot 19^{2}\right)=1.11 \cdots$. Hence the only possibility is $19 \| n$. Since $H\left(2^{2} \cdot 7^{2} \cdot 19\right)=(2 \cdot 3 \cdot 7) / 5$, it is necessary that $5 \mid n$. In fact, $H\left(2^{2} \cdot 7^{2} \cdot 19 \cdot 5\right)=14$, so we get the solution $n=18620$.

Suppose that $s=1$ and $t=2$. Since $H\left(2 \cdot 7^{2}\right)=\left(2^{2} \cdot 7^{2}\right) /(3 \cdot 19)$, it is necessary that $19 \mid n$. If $19^{4} \mid n$, then $H(n) \geq H\left(2 \cdot 7^{2} \cdot 19^{4}\right)>14$. If $n=2 \cdot 7^{2} \cdot 19^{3} m$ with $(m, 266)=1$, then $H(m)=14 / H\left(2 \cdot 7^{2} \cdot 19^{3}\right)=1.07 \cdots$. If $n=2 \cdot 7^{2} \cdot 19^{2} m$ with $(m, 266)=1$, then $H(m)=14 / H\left(2 \cdot 7^{2} \cdot 19^{2}\right)=1.43 \cdots$. Hence we have $19 \| n$ and $n=2 \cdot 7^{2} \cdot 19 m$ with $(m, 266)=1$. Since $H\left(2 \cdot 7^{2} \cdot 19\right)=\left(2 \cdot 7^{2}\right) /(3 \cdot 5)$, it is necessary that $5 \mid m$. If $5^{2} \mid m$, then $H(n) \geq H\left(2 \cdot 7^{2} \cdot 19 \cdot 5^{2}\right)>14$. If $n=2 \cdot 7^{2} \cdot 19 \cdot 5 m^{\prime}$ with $\left(m^{\prime}, 1330\right)=1$, then $H\left(m^{\prime}\right)=14 / H\left(2 \cdot 7^{2} \cdot 19 \cdot 5\right)=1.28 \cdots$, a contradiction.

We have checked all possibilities; hence 18620 is the only solution of $H(n)=14$.

\section{Open PROBlems}

The problems in this section are proposed by the pioneers or the authors.

Problem 1. Does a nontrivial odd harmonic number exist?

Ore conjectured that the answer is "no". If the conjecture is true, then odd perfect numbers do not exist.

Problem 2. Are there infinitely many harmonic numbers? How about harmonic seeds?

It seems that the answer to this problem is "yes", but it is not clear. On this topic, the authors' question is as follows.

Problem 3. Are there infinitely many harmonic seeds $n$ with $\omega(n)=3$ ? If not, find all such $n$. Does an odd one exist?

All such numbers which the authors know are $n=270$ with $H(n)=6, n=672$ with $H(n)=8$, and $n=6200$ with $H(n)=10$. How about the same problem with $\omega(n)=4,5, \ldots$ ? Note that there exist only finitely many harmonic numbers with a fixed type of exponents, because of the inequality $H(n)<\tau(n)$ and Theorem 1.2

Cohen and Sorli [3] conjectured that a harmonic seed of a harmonic number is always unique. 
Problem 4. Does every harmonic number have a unique harmonic seed?

We say that $n$ is powerful if $p \mid n$ implies $p^{2} \mid n$, where $p$ is prime. Cohen and Sorli [3] implied that nontrivial harmonic numbers are not powerful.

Problem 5. Does a nontrivial powerful harmonic number exist?

It is showed that there are no nontrivial powerful harmonic numbers less than $10^{12}$ in [3]. Euler showed that the factorization of an odd perfect number must have the form $p^{e} p_{1}^{2 e_{1}} \cdots p_{r}^{2 e_{r}}$ with $p \equiv e \equiv 1(\bmod 4)$. If odd powerful harmonic numbers other than 1 do not exist, the form of an odd perfect number must be $p p_{1}^{2 e_{1}} \cdots p_{r}^{2 e_{r}}$ with $p \equiv 1(\bmod 4)$.

Nontrivial harmonic numbers listed in Table 4 are perfect numbers or abundant numbers. In other words, if $H(n)$ is integral and $1<H(n) \leq 300$, then $S(n)=$ $\sigma(n) / n \geq 2$.

Problem 6. Does a nontrivial deficient harmonic number exist?

A harmonic number $n$ is deficient if and only if $H(n)>\tau(n) / 2$. Cohen and Deng [4] remarked that $H(n)<2 \tau(n) / 3$ for an even harmonic number $n$.

A positive integer $n$ is said to be arithmetic if the arithmetic mean of its positive divisors $A(n)=\sigma(n) / \tau(n)$ is an integer. For example, odd primes are arithmetic. Ore observed that almost all (small) harmonic numbers $n$ with $\omega(n) \geq 3$ are arithmetic and conjectured that all such numbers are arithmetic. But he soon found the counterexample 950976. Such counterexamples are marked with an asterisk in Table 4. On this topic, the following facts hold.

Proposition 6.1. Let $n$ be harmonic. Then $n$ is arithmetic if and only if $H(n) \mid n$. In particular, even perfect numbers are not arithmetic.

Proof. The first statement is clear from the equation $H(n) A(n)=n$. Since $H(n)=$ $p$ for an even perfect number $n=2^{p-1}\left(2^{p}-1\right)$, the second statement is also clear.

In view of Proposition 6.1 Proposition 1.5 says: "If $H(n)$ is a prime and $n$ is not an even perfect number, then $n$ is arithmetic." And the first statement of Proposition 1.4 says: "If $H(n)$ is a double of a prime, then $n$ is arithmetic."

Problem 7. Assume that $H(n)$ is a triple of a prime. Is $n$ arithmetic?

If $H(n)$ is a triple of a prime and less than 300 , then $n$ is arithmetic. But it is not clear whether or not 3 divides $n$ when $H(n)>300$. 
TABLE 4. All harmonic numbers with $H(n) \leq 300$

\begin{tabular}{|c|c|c|c|}
\hline$H(n)$ & $n$ & factorization of $n$ & seed \\
\hline 1 & 1 & & \\
\hline 2 & 6 & $2 \cdot 3$ & seed \\
\hline 3 & 28 & $2^{2} \cdot 7$ & seed \\
\hline \multirow[t]{2}{*}{5} & 140 & $2^{2} \cdot 5 \cdot 7$ & $2^{2} \cdot 7$ \\
\hline & 496 & $2^{4} \cdot 31$ & seed \\
\hline 6 & 270 & $2 \cdot 3^{3} \cdot 5$ & seed \\
\hline 7 & 8128 & $2^{6} \cdot 127$ & seed \\
\hline 8 & 672 & $2^{5} \cdot 3 \cdot 7$ & seed \\
\hline 9 & 1638 & $2 \cdot 3^{2} \cdot 7 \cdot 13$ & seed \\
\hline 10 & 6200 & $2^{3} \cdot 5^{2} \cdot 31$ & seed \\
\hline 11 & 2970 & $2 \cdot 3^{3} \cdot 5 \cdot 11$ & $2 \cdot 3^{3} \cdot 5$ \\
\hline \multirow[t]{2}{*}{13} & 105664 & $2^{6} \cdot 13 \cdot 127$ & $2^{6} \cdot 127$ \\
\hline & 33550336 & $2^{12} \cdot 8191$ & seed \\
\hline 14 & 18620 & $2^{2} \cdot 5 \cdot 7^{2} \cdot 19$ & seed \\
\hline \multirow[t]{2}{*}{15} & 8190 & $2 \cdot 3^{2} \cdot 5 \cdot 7 \cdot 13$ & $2 \cdot 3^{2} \cdot 7 \cdot 13$ \\
\hline & 18600 & $2^{3} \cdot 3 \cdot 5^{2} \cdot 31$ & $2^{3} \cdot 5^{2} \cdot 31$ \\
\hline \multirow[t]{2}{*}{17} & 27846 & $2 \cdot 3^{2} \cdot 7 \cdot 13 \cdot 17$ & $2 \cdot 3^{2} \cdot 7 \cdot 13$ \\
\hline & 8589869056 & $2^{16} \cdot 131071$ & seed \\
\hline \multirow[t]{2}{*}{19} & 117800 & $2^{3} \cdot 5^{2} \cdot 19 \cdot 31$ & $2^{3} \cdot 5^{2} \cdot 31$ \\
\hline & 137438691328 & $2^{18} \cdot 524287$ & seed \\
\hline 21 & 55860 & $2^{2} \cdot 3 \cdot 5 \cdot 7^{2} \cdot 19$ & $2^{2} \cdot 5 \cdot 7^{2} \cdot 19$ \\
\hline \multirow[t]{2}{*}{24} & 30240 & $2^{5} \cdot 3^{3} \cdot 5 \cdot 7$ & seed \\
\hline & 32760 & $2^{3} \cdot 3^{2} \cdot 5 \cdot 7 \cdot 13$ & seed \\
\hline 25 & 173600 & $2^{5} \cdot 5^{2} \cdot 7 \cdot 31$ & seed \\
\hline 26 & 242060 & $2^{2} \cdot 5 \cdot 7^{2} \cdot 13 \cdot 19$ & $2^{2} \cdot 5 \cdot 7^{2} \cdot 19$ \\
\hline \multirow[t]{3}{*}{27} & 167400 & $2^{3} \cdot 3^{3} \cdot 5^{2} \cdot 31$ & $2^{3} \cdot 5^{2} \cdot 31$ \\
\hline & ${ }^{*} 950976$ & $2^{6} \cdot 3^{2} \cdot 13 \cdot 127$ & $2^{6} \cdot 127$ \\
\hline & *301953024 & $2^{12} \cdot 3^{2} \cdot 8191$ & $2^{12} \cdot 8191$ \\
\hline \multirow[t]{2}{*}{29} & 237510 & $2 \cdot 3^{2} \cdot 5 \cdot 7 \cdot 13 \cdot 29$ & $2 \cdot 3^{2} \cdot 7 \cdot 13$ \\
\hline & 539400 & $2^{3} \cdot 3 \cdot 5^{2} \cdot 29 \cdot 31$ & $2^{3} \cdot 5^{2} \cdot 31$ \\
\hline 31 & $23 \cdots 8139952128$ & $2^{30} \cdot\left(2^{31}-1\right)$ & seed \\
\hline 35 & 2229500 & $2^{2} \cdot 5^{3} \cdot 7^{3} \cdot 13$ & seed \\
\hline \multirow[t]{2}{*}{37} & 4358600 & $2^{3} \cdot 5^{2} \cdot 19 \cdot 31 \cdot 37$ & $2^{3} \cdot 5^{2} \cdot 31$ \\
\hline & 5085231579136 & $2^{18} \cdot 37 \cdot 524287$ & $2^{18} \cdot 524287$ \\
\hline 39 & 726180 & $2^{2} \cdot 3 \cdot 5 \cdot 7^{2} \cdot 13 \cdot 19$ & $2^{2} \cdot 5 \cdot 7^{2} \cdot 19$ \\
\hline 41 & 2290260 & $2^{2} \cdot 3 \cdot 5 \cdot 7^{2} \cdot 19 \cdot 41$ & $2^{2} \cdot 5 \cdot 7^{2} \cdot 19$ \\
\hline 42 & 1089270 & $2 \cdot 3^{2} \cdot 5 \cdot 7^{2} \cdot 13 \cdot 19$ & seed \\
\hline \multirow[t]{2}{*}{44} & 332640 & $2^{5} \cdot 3^{3} \cdot 5 \cdot 7 \cdot 11$ & $2^{5} \cdot 3^{3} \cdot 5 \cdot 7$ \\
\hline & 360360 & $2^{3} \cdot 3^{2} \cdot 5 \cdot 7 \cdot 11 \cdot 13$ & $2^{3} \cdot 3^{2} \cdot 5 \cdot 7 \cdot 13$ \\
\hline \multirow[t]{2}{*}{45} & 4754880 & $2^{6} \cdot 3^{2} \cdot 5 \cdot 13 \cdot 127$ & $2^{6} \cdot 127$ \\
\hline & 1509765120 & $2^{12} \cdot 3^{2} \cdot 5 \cdot 8191$ & $2^{12} \cdot 8191$ \\
\hline 46 & 695520 & $2^{5} \cdot 3^{3} \cdot 5 \cdot 7 \cdot 23$ & $2^{5} \cdot 3^{3} \cdot 5 \cdot 7$ \\
\hline
\end{tabular}


TABle 4. (continued)

\begin{tabular}{|c|c|c|c|}
\hline$H(n)$ & $n$ & factorization of $n$ & seed \\
\hline \multirow{3}{*}{47} & 753480 & $2^{3} \cdot 3^{2} \cdot 5 \cdot 7 \cdot 13 \cdot 23$ & $2^{3} \cdot 3^{2} \cdot 5 \cdot 7 \cdot 13$ \\
\hline & 1421280 & $2^{5} \cdot 3^{3} \cdot 5 \cdot 7 \cdot 47$ & $2^{5} \cdot 3^{3} \cdot 5 \cdot 7$ \\
\hline & 1539720 & $2^{3} \cdot 3^{2} \cdot 5 \cdot 7 \cdot 13 \cdot 47$ & $2^{3} \cdot 3^{2} \cdot 5 \cdot 7 \cdot 13$ \\
\hline 48 & 4713984 & $2^{9} \cdot 3^{3} \cdot 11 \cdot 31$ & seed \\
\hline \multirow[t]{3}{*}{49} & 5772200 & $2^{3} \cdot 5^{2} \cdot 7^{2} \cdot 19 \cdot 31$ & $2^{3} \cdot 5^{2} \cdot 31$ \\
\hline & 8506400 & $2^{5} \cdot 5^{2} \cdot 7^{3} \cdot 31$ & seed \\
\hline & 6734495875072 & $2^{18} \cdot 7^{2} \cdot 524287$ & $2^{18} \cdot 524287$ \\
\hline 50 & 6051500 & $2^{2} \cdot 5^{3} \cdot 7^{2} \cdot 13 \cdot 19$ & seed \\
\hline \multirow[t]{3}{*}{51} & 2845800 & $2^{3} \cdot 3^{3} \cdot 5^{2} \cdot 17 \cdot 31$ & $2^{3} \cdot 5^{2} \cdot 31$ \\
\hline & 16166592 & $2^{6} \cdot 3^{2} \cdot 13 \cdot 17 \cdot 127$ & $2^{6} \cdot 127$ \\
\hline & 5133201408 & $2^{12} \cdot 3^{2} \cdot 17 \cdot 8191$ & $2^{12} \cdot 8191$ \\
\hline \multirow[t]{3}{*}{53} & 8872200 & $2^{3} \cdot 3^{3} \cdot 5^{2} \cdot 31 \cdot 53$ & $2^{3} \cdot 5^{2} \cdot 31$ \\
\hline & 50401728 & $2^{6} \cdot 3^{2} \cdot 13 \cdot 53 \cdot 127$ & $2^{6} \cdot 127$ \\
\hline & 16003510272 & $2^{12} \cdot 3^{2} \cdot 53 \cdot 8191$ & $2^{12} \cdot 8191$ \\
\hline 54 & ${ }^{*} 2178540$ & $2^{2} \cdot 3^{2} \cdot 5 \cdot 7^{2} \cdot 13 \cdot 19$ & $2^{2} \cdot 5 \cdot 7^{2} \cdot 19$ \\
\hline 60 & 2457000 & $2^{3} \cdot 3^{3} \cdot 5^{3} \cdot 7 \cdot 13$ & seed \\
\hline \multirow[t]{2}{*}{61} & $14 \cdots 6537079808$ & $2^{30} \cdot 61 \cdot\left(2^{31}-1\right)$ & $2^{30} \cdot\left(2^{31}-1\right)$ \\
\hline & $26 \cdots 5953842176$ & $2^{60} \cdot\left(2^{61}-1\right)$ & seed \\
\hline 70 & 23088800 & $2^{5} \cdot 5^{2} \cdot 7^{2} \cdot 19 \cdot 31$ & seed \\
\hline \multirow[t]{2}{*}{73} & 318177800 & $2^{3} \cdot 5^{2} \cdot 19 \cdot 31 \cdot 37 \cdot 73$ & $2^{3} \cdot 5^{2} \cdot 31$ \\
\hline & 371221905276928 & $2^{18} \cdot 37 \cdot 73 \cdot 524287$ & $2^{18} \cdot 524287$ \\
\hline \multirow[t]{2}{*}{75} & 18154500 & $2^{2} \cdot 3 \cdot 5^{3} \cdot 7^{2} \cdot 13 \cdot 19$ & $2^{2} \cdot 5^{3} \cdot 7^{2} \cdot 13 \cdot 19$ \\
\hline & *57 *3498803200 & $2^{30} \cdot 5^{2} \cdot\left(2^{31}-1\right)$ & $2^{30} \cdot\left(2^{31}-1\right)$ \\
\hline 77 & 11981970 & $2 \cdot 3^{2} \cdot 5 \cdot 7^{2} \cdot 11 \cdot 13 \cdot 19$ & $2 \cdot 3^{2} \cdot 5 \cdot 7^{2} \cdot 13 \cdot 19$ \\
\hline 78 & 115048440 & $2^{3} \cdot 3^{2} \cdot 5 \cdot 13^{2} \cdot 31 \cdot 61$ & seed \\
\hline 80 & 23569920 & $2^{9} \cdot 3^{3} \cdot 5 \cdot 11 \cdot 31$ & $2^{9} \cdot 3^{3} \cdot 11 \cdot 31$ \\
\hline 81 & 29410290 & $2 \cdot 3^{5} \cdot 5 \cdot 7^{2} \cdot 13 \cdot 19$ & seed \\
\hline 82 & 44660070 & $2 \cdot 3^{2} \cdot 5 \cdot 7^{2} \cdot 13 \cdot 19 \cdot 41$ & $2 \cdot 3^{2} \cdot 5 \cdot 7^{2} \cdot 13 \cdot 19$ \\
\hline 83 & 90409410 & $2 \cdot 3^{2} \cdot 5 \cdot 7^{2} \cdot 13 \cdot 19 \cdot 83$ & $2 \cdot 3^{2} \cdot 5 \cdot 7^{2} \cdot 13 \cdot 19$ \\
\hline 84 & 32997888 & $2^{9} \cdot 3^{3} \cdot 7 \cdot 11 \cdot 31$ & $2^{9} \cdot 3^{3} \cdot 11 \cdot 31$ \\
\hline \multirow[t]{2}{*}{85} & 80832960 & $2^{6} \cdot 3^{2} \cdot 5 \cdot 13 \cdot 17 \cdot 127$ & $2^{6} \cdot 127$ \\
\hline & 25666007040 & $2^{12} \cdot 3^{2} \cdot 5 \cdot 17 \cdot 8191$ & $2^{12} \cdot 8191$ \\
\hline \multirow[t]{2}{*}{86} & 14303520 & $2^{5} \cdot 3^{3} \cdot 5 \cdot 7 \cdot 11 \cdot 43$ & $2^{5} \cdot 3^{3} \cdot 5 \cdot 7$ \\
\hline & 15495480 & $2^{3} \cdot 3^{2} \cdot 5 \cdot 7 \cdot 11 \cdot 13 \cdot 43$ & $2^{3} \cdot 3^{2} \cdot 5 \cdot 7 \cdot 13$ \\
\hline \multirow[t]{2}{*}{87} & 137891520 & $2^{6} \cdot 3^{2} \cdot 5 \cdot 13 \cdot 29 \cdot 127$ & $2^{6} \cdot 127$ \\
\hline & 43783188480 & $2^{12} \cdot 3^{2} \cdot 5 \cdot 29 \cdot 8191$ & $2^{12} \cdot 8191$ \\
\hline 88 & 255428096 & $2^{9} \cdot 7 \cdot 11^{2} \cdot 19 \cdot 31$ & seed \\
\hline \multirow[t]{3}{*}{89} & 423184320 & $2^{6} \cdot 3^{2} \cdot 5 \cdot 13 \cdot 89 \cdot 127$ & $2^{6} \cdot 127$ \\
\hline & 134369095680 & $2^{12} \cdot 3^{2} \cdot 5 \cdot 89 \cdot 8191$ & $2^{12} \cdot 8191$ \\
\hline & $19 \cdots 1548169216$ & $2^{88} \cdot\left(2^{89}-1\right)$ & seed \\
\hline \multirow[t]{2}{*}{91} & 75038600 & $2^{3} \cdot 5^{2} \cdot 7^{2} \cdot 13 \cdot 19 \cdot 31$ & $2^{3} \cdot 5^{2} \cdot 31$ \\
\hline & 110583200 & $2^{5} \cdot 5^{2} \cdot 7^{3} \cdot 13 \cdot 31$ & $2^{5} \cdot 5^{2} \cdot 7^{3} \cdot 31$ \\
\hline
\end{tabular}


TABLE 4. (continued)

\begin{tabular}{|c|c|c|c|}
\hline$H(n)$ & $n$ & factorization of $n$ & seed \\
\hline & 87548446375936 & $2^{18} \cdot 7^{2} \cdot 13 \cdot 524287$ & $2^{18} \cdot 524287$ \\
\hline 92 & 108421632 & $2^{9} \cdot 3^{3} \cdot 11 \cdot 23 \cdot 31$ & $2^{9} \cdot 3^{3} \cdot 11 \cdot 31$ \\
\hline 94 & 221557248 & $2^{9} \cdot 3^{3} \cdot 11 \cdot 31 \cdot 47$ & $2^{9} \cdot 3^{3} \cdot 11 \cdot 31$ \\
\hline \multirow[t]{4}{*}{96} & 17428320 & $2^{5} \cdot 3^{2} \cdot 5 \cdot 7^{2} \cdot 13 \cdot 19$ & seed \\
\hline & 45532800 & $2^{7} \cdot 3^{3} \cdot 5^{2} \cdot 17 \cdot 31$ & seed \\
\hline & *459818240 & $2^{8} \cdot 5 \cdot 7 \cdot 19 \cdot 37 \cdot 73$ & seed \\
\hline & *10200236032 & $2^{14} \cdot 7 \cdot 19 \cdot 31 \cdot 151$ & seed \\
\hline \multirow[t]{3}{*}{97} & 559903400 & $2^{3} \cdot 5^{2} \cdot 7^{2} \cdot 19 \cdot 31 \cdot 97$ & $2^{3} \cdot 5^{2} \cdot 31$ \\
\hline & 825120800 & $2^{5} \cdot 5^{2} \cdot 7^{3} \cdot 31 \cdot 97$ & $2^{5} \cdot 5^{2} \cdot 7^{3} \cdot 31$ \\
\hline & 653246099881984 & $2^{18} \cdot 7^{2} \cdot 97 \cdot 524287$ & $2^{18} \cdot 524287$ \\
\hline \multirow[t]{2}{*}{99} & 23963940 & $2^{2} \cdot 3^{2} \cdot 5 \cdot 7^{2} \cdot 11 \cdot 13 \cdot 19$ & $2^{2} \cdot 5 \cdot 7^{2} \cdot 19$ \\
\hline & 1630964808 & $2^{3} \cdot 3^{4} \cdot 11^{3} \cdot 31 \cdot 61$ & seed \\
\hline \multirow[t]{3}{*}{101} & 287425800 & $2^{3} \cdot 3^{3} \cdot 5^{2} \cdot 17 \cdot 31 \cdot 101$ & $2^{3} \cdot 5^{2} \cdot 31$ \\
\hline & 1632825792 & $2^{6} \cdot 3^{2} \cdot 13 \cdot 17 \cdot 101 \cdot 127$ & $2^{6} \cdot 127$ \\
\hline & 518453342208 & $2^{12} \cdot 3^{2} \cdot 17 \cdot 101 \cdot 8191$ & $2^{12} \cdot 8191$ \\
\hline 102 & 37035180 & $2^{2} \cdot 3^{2} \cdot 5 \cdot 7^{2} \cdot 13 \cdot 17 \cdot 19$ & $2^{2} \cdot 5 \cdot 7^{2} \cdot 19$ \\
\hline \multirow[t]{2}{*}{105} & 69266400 & $2^{5} \cdot 3 \cdot 5^{2} \cdot 7^{2} \cdot 19 \cdot 31$ & $2^{5} \cdot 5^{2} \cdot 7^{2} \cdot 19 \cdot 31$ \\
\hline & 81695250 & $2 \cdot 3^{3} \cdot 5^{3} \cdot 7^{2} \cdot 13 \cdot 19$ & seed \\
\hline 106 & 115462620 & $2^{2} \cdot 3^{2} \cdot 5 \cdot 7^{2} \cdot 13 \cdot 19 \cdot 53$ & $2^{2} \cdot 5 \cdot 7^{2} \cdot 19$ \\
\hline \multirow[t]{2}{*}{107} & 233103780 & $2^{2} \cdot 3^{2} \cdot 5 \cdot 7^{2} \cdot 13 \cdot 19 \cdot 107$ & $2^{2} \cdot 5 \cdot 7^{2} \cdot 19$ \\
\hline & $13 \cdots 7783728128$ & $2^{106} \cdot\left(2^{107}-1\right)$ & seed \\
\hline 108 & 52141320 & $2^{3} \cdot 3^{4} \cdot 5 \cdot 7 \cdot 11^{2} \cdot 19$ & seed \\
\hline 110 & 27027000 & $2^{3} \cdot 3^{3} \cdot 5^{3} \cdot 7 \cdot 11 \cdot 13$ & $2^{3} \cdot 3^{3} \cdot 5^{3} \cdot 7 \cdot 13$ \\
\hline 114 & 46683000 & $2^{3} \cdot 3^{3} \cdot 5^{3} \cdot 7 \cdot 13 \cdot 19$ & $2^{3} \cdot 3^{3} \cdot 5^{3} \cdot 7 \cdot 13$ \\
\hline 115 & 56511000 & $2^{3} \cdot 3^{3} \cdot 5^{3} \cdot 7 \cdot 13 \cdot 23$ & $2^{3} \cdot 3^{3} \cdot 5^{3} \cdot 7 \cdot 13$ \\
\hline 116 & 71253000 & $2^{3} \cdot 3^{3} \cdot 5^{3} \cdot 7 \cdot 13 \cdot 29$ & $2^{3} \cdot 3^{3} \cdot 5^{3} \cdot 7 \cdot 13$ \\
\hline 117 & 644271264 & $2^{5} \cdot 3^{2} \cdot 7 \cdot 13^{2} \cdot 31 \cdot 61$ & seed \\
\hline 118 & 144963000 & $2^{3} \cdot 3^{3} \cdot 5^{3} \cdot 7 \cdot 13 \cdot 59$ & $2^{3} \cdot 3^{3} \cdot 5^{3} \cdot 7 \cdot 13$ \\
\hline 120 & *142990848 & $2^{9} \cdot 3^{2} \cdot 7 \cdot 11 \cdot 13 \cdot 31$ & seed \\
\hline 121 & 8698459616 & $2^{5} \cdot 7^{2} \cdot 11^{2} \cdot 19^{2} \cdot 127$ & seed \\
\hline 125 & ${ }^{*} 73924348400$ & $2^{4} \cdot 5^{2} \cdot 7 \cdot 31^{2} \cdot 83 \cdot 331$ & seed \\
\hline 127 & $14 \cdots 1199152128$ & $2^{126} \cdot\left(2^{127}-1\right)$ & seed \\
\hline 128 & 1867650048 & $2^{10} \cdot 3^{4} \cdot 11 \cdot 23 \cdot 89$ & seed \\
\hline 130 & 300154400 & $2^{5} \cdot 5^{2} \cdot 7^{2} \cdot 13 \cdot 19 \cdot 31$ & $2^{5} \cdot 5^{2} \cdot 7^{2} \cdot 19 \cdot 31$ \\
\hline 132 & 766284288 & $2^{9} \cdot 3 \cdot 7 \cdot 11^{2} \cdot 19 \cdot 31$ & $2^{9} \cdot 7 \cdot 11^{2} \cdot 19 \cdot 31$ \\
\hline 135 & 163390500 & $2^{2} \cdot 3^{3} \cdot 5^{3} \cdot 7^{2} \cdot 13 \cdot 19$ & $2^{2} \cdot 5^{3} \cdot 7^{2} \cdot 13 \cdot 19$ \\
\hline 139 & 3209343200 & $2^{5} \cdot 5^{2} \cdot 7^{2} \cdot 19 \cdot 31 \cdot 139$ & $2^{5} \cdot 5^{2} \cdot 7^{2} \cdot 19 \cdot 31$ \\
\hline 140 & 164989440 & $2^{9} \cdot 3^{3} \cdot 5 \cdot 7 \cdot 11 \cdot 31$ & $2^{9} \cdot 3^{3} \cdot 11 \cdot 31$ \\
\hline 143 & 1265532840 & $2^{3} \cdot 3^{2} \cdot 5 \cdot 11 \cdot 13^{2} \cdot 31 \cdot 61$ & $2^{3} \cdot 3^{2} \cdot 5 \cdot 13^{2} \cdot 31 \cdot 61$ \\
\hline \multirow[t]{2}{*}{144} & *1379454720 & $2^{8} \cdot 3 \cdot 5 \cdot 7 \cdot 19 \cdot 37 \cdot 73$ & $2^{8} \cdot 5 \cdot 7 \cdot 19 \cdot 37 \cdot 73$ \\
\hline & ${ }^{*} 30600708096$ & $2^{14} \cdot 3 \cdot 7 \cdot 19 \cdot 31 \cdot 151$ & $2^{14} \cdot 7 \cdot 19 \cdot 31 \cdot 151$ \\
\hline 145 & 526480500 & $2^{2} \cdot 3 \cdot 5^{3} \cdot 7^{2} \cdot 13 \cdot 19 \cdot 29$ & $2^{2} \cdot 5^{3} \cdot 7^{2} \cdot 13 \cdot 19$ \\
\hline
\end{tabular}


TABle 4. (continued)

\begin{tabular}{|c|c|c|c|}
\hline$H(n)$ & $n$ & factorization of $n$ & seed \\
\hline & $16 \cdots 1465292800$ & $2^{30} \cdot 5^{2} \cdot 29 \cdot\left(2^{31}-1\right)$ & $2^{30} \cdot\left(2^{31}-1\right)$ \\
\hline 147 & 4409499089268 & $2^{2} \cdot 3^{3} \cdot 7^{4} \cdot 13 \cdot 467 \cdot 2801$ & seed \\
\hline \multirow[t]{2}{*}{149} & 2705020500 & $2^{2} \cdot 3 \cdot 5^{3} \cdot 7^{2} \cdot 13 \cdot 19 \cdot 149$ & $2^{2} \cdot 5^{3} \cdot 7^{2} \cdot 13 \cdot 19$ \\
\hline & $85 \cdots 1321676800$ & $2^{30} \cdot 5^{2} \cdot 149 \cdot\left(2^{31}-1\right)$ & $2^{30} \cdot\left(2^{31}-1\right)$ \\
\hline 150 & 2876211000 & $2^{3} \cdot 3^{2} \cdot 5^{3} \cdot 13^{2} \cdot 31 \cdot 61$ & seed \\
\hline 152 & 447828480 & $2^{9} \cdot 3^{3} \cdot 5 \cdot 11 \cdot 19 \cdot 31$ & $2^{9} \cdot 3^{3} \cdot 11 \cdot 31$ \\
\hline 153 & 499974930 & $2 \cdot 3^{5} \cdot 5 \cdot 7^{2} \cdot 13 \cdot 17 \cdot 19$ & $2 \cdot 3^{5} \cdot 5 \cdot 7^{2} \cdot 13 \cdot 19$ \\
\hline 155 & 110886522600 & $2^{3} \cdot 3 \cdot 5^{2} \cdot 7 \cdot 31^{2} \cdot 83 \cdot 331$ & seed \\
\hline 156 & 428972544 & $2^{9} \cdot 3^{3} \cdot 7 \cdot 11 \cdot 13 \cdot 31$ & $2^{9} \cdot 3^{3} \cdot 11 \cdot 31$ \\
\hline 158 & 1862023680 & $2^{9} \cdot 3^{3} \cdot 5 \cdot 11 \cdot 31 \cdot 79$ & $2^{9} \cdot 3^{3} \cdot 11 \cdot 31$ \\
\hline 159 & 1558745370 & $2 \cdot 3^{5} \cdot 5 \cdot 7^{2} \cdot 13 \cdot 19 \cdot 53$ & $2 \cdot 3^{5} \cdot 5 \cdot 7^{2} \cdot 13 \cdot 19$ \\
\hline 160 & 51001180160 & $2^{14} \cdot 5 \cdot 7 \cdot 19 \cdot 31 \cdot 151$ & $2^{14} \cdot 7 \cdot 19 \cdot 31 \cdot 151$ \\
\hline 161 & 758951424 & $2^{9} \cdot 3^{3} \cdot 7 \cdot 11 \cdot 23 \cdot 31$ & $2^{9} \cdot 3^{3} \cdot 11 \cdot 31$ \\
\hline 163 & 7279591410 & $2 \cdot 3^{2} \cdot 5 \cdot 7^{2} \cdot 13 \cdot 19 \cdot 41 \cdot 163$ & $2 \cdot 3^{2} \cdot 5 \cdot 7^{2} \cdot 13 \cdot 19$ \\
\hline 164 & 1352913408 & $2^{9} \cdot 3^{3} \cdot 7 \cdot 11 \cdot 31 \cdot 41$ & $2^{9} \cdot 3^{3} \cdot 11 \cdot 31$ \\
\hline 165 & 8154824040 & $2^{3} \cdot 3^{4} \cdot 5 \cdot 11^{3} \cdot 31 \cdot 61$ & $2^{3} \cdot 3^{4} \cdot 11^{3} \cdot 31 \cdot 61$ \\
\hline 166 & 2738824704 & $2^{9} \cdot 3^{3} \cdot 7 \cdot 11 \cdot 31 \cdot 83$ & $2^{9} \cdot 3^{3} \cdot 11 \cdot 31$ \\
\hline 167 & 5510647296 & $2^{9} \cdot 3^{3} \cdot 7 \cdot 11 \cdot 31 \cdot 167$ & $2^{9} \cdot 3^{3} \cdot 11 \cdot 31$ \\
\hline \multirow[t]{3}{*}{168} & 318729600 & $2^{7} \cdot 3^{3} \cdot 5^{2} \cdot 7 \cdot 17 \cdot 31$ & $2^{7} \cdot 3^{3} \cdot 5^{2} \cdot 17 \cdot 31$ \\
\hline & 326781000 & $2^{3} \cdot 3^{3} \cdot 5^{3} \cdot 7^{2} \cdot 13 \cdot 19$ & seed \\
\hline & 481572000 & $2^{5} \cdot 3^{3} \cdot 5^{3} \cdot 7^{3} \cdot 13$ & seed \\
\hline \multirow[t]{3}{*}{169} & 13660770240 & $2^{6} \cdot 3^{2} \cdot 5 \cdot 13^{3} \cdot 17 \cdot 127$ & $2^{6} \cdot 127$ \\
\hline & $23 \cdots 4766487552$ & $2^{30} \cdot 13^{2} \cdot 61 \cdot\left(2^{31}-1\right)$ & $2^{30} \cdot\left(2^{31}-1\right)$ \\
\hline & $44 \cdots 6199327744$ & $2^{60} \cdot 13^{2} \cdot\left(2^{61}-1\right)$ & $2^{60} \cdot\left(2^{61}-1\right)$ \\
\hline \multirow[t]{2}{*}{171} & 8410907232 & $2^{5} \cdot 3^{2} \cdot 7^{2} \cdot 13 \cdot 19^{2} \cdot 127$ & seed \\
\hline & *221908282624 & $2^{8} \cdot 7 \cdot 19^{2} \cdot 37 \cdot 73 \cdot 127$ & seed \\
\hline 172 & 10983408128 & $2^{9} \cdot 7 \cdot 11^{2} \cdot 19 \cdot 31 \cdot 43$ & $2^{9} \cdot 7 \cdot 11^{2} \cdot 19 \cdot 31$ \\
\hline \multirow[t]{2}{*}{173} & 23855232960 & $2^{6} \cdot 3^{2} \cdot 5 \cdot 13 \cdot 29 \cdot 127 \cdot 173$ & $2^{6} \cdot 127$ \\
\hline & 7574491607040 & $2^{12} \cdot 3^{2} \cdot 5 \cdot 29 \cdot 173 \cdot 8191$ & $2^{12} \cdot 8191$ \\
\hline \multirow[t]{4}{*}{176} & 191711520 & $2^{5} \cdot 3^{2} \cdot 5 \cdot 7^{2} \cdot 11 \cdot 13 \cdot 19$ & $2^{5} \cdot 3^{2} \cdot 5 \cdot 7^{2} \cdot 13 \cdot 19$ \\
\hline & 500860800 & $2^{7} \cdot 3^{3} \cdot 5^{2} \cdot 11 \cdot 17 \cdot 31$ & $2^{7} \cdot 3^{3} \cdot 5^{2} \cdot 17 \cdot 31$ \\
\hline & 5058000640 & $2^{8} \cdot 5 \cdot 7 \cdot 11 \cdot 19 \cdot 37 \cdot 73$ & $2^{8} \cdot 5 \cdot 7 \cdot 19 \cdot 37 \cdot 73$ \\
\hline & 112202596352 & $2^{14} \cdot 7 \cdot 11 \cdot 19 \cdot 31 \cdot 151$ & $2^{14} \cdot 7 \cdot 19 \cdot 31 \cdot 151$ \\
\hline \multirow[t]{3}{*}{181} & 13581986600 & $2^{3} \cdot 5^{2} \cdot 7^{2} \cdot 13 \cdot 19 \cdot 31 \cdot 181$ & $2^{3} \cdot 5^{2} \cdot 31$ \\
\hline & 20015559200 & $2^{5} \cdot 5^{2} \cdot 7^{3} \cdot 13 \cdot 31 \cdot 181$ & $2^{5} \cdot 5^{2} \cdot 7^{3} \cdot 31$ \\
\hline & $15 \cdots 8794044416$ & $2^{18} \cdot 7^{2} \cdot 13 \cdot 181 \cdot 524287$ & $2^{18} \cdot 524287$ \\
\hline \multirow[t]{4}{*}{184} & 400851360 & $2^{5} \cdot 3^{2} \cdot 5 \cdot 7^{2} \cdot 13 \cdot 19 \cdot 23$ & $2^{5} \cdot 3^{2} \cdot 5 \cdot 7^{2} \cdot 13 \cdot 19$ \\
\hline & 1047254400 & $2^{7} \cdot 3^{3} \cdot 5^{2} \cdot 17 \cdot 23 \cdot 31$ & $2^{7} \cdot 3^{3} \cdot 5^{2} \cdot 17 \cdot 31$ \\
\hline & 10575819520 & $2^{8} \cdot 5 \cdot 7 \cdot 19 \cdot 23 \cdot 37 \cdot 73$ & $2^{8} \cdot 5 \cdot 7 \cdot 19 \cdot 37 \cdot 73$ \\
\hline & 234605428736 & $2^{14} \cdot 7 \cdot 19 \cdot 23 \cdot 31 \cdot 151$ & $2^{14} \cdot 7 \cdot 19 \cdot 31 \cdot 151$ \\
\hline \multirow[t]{2}{*}{186} & 540277920 & $2^{5} \cdot 3^{2} \cdot 5 \cdot 7^{2} \cdot 13 \cdot 19 \cdot 31$ & $2^{5} \cdot 3^{2} \cdot 5 \cdot 7^{2} \cdot 13 \cdot 19$ \\
\hline & ${ }^{*} 14254365440$ & $2^{8} \cdot 5 \cdot 7 \cdot 19 \cdot 31 \cdot 37 \cdot 73$ & $2^{8} \cdot 5 \cdot 7 \cdot 19 \cdot 37 \cdot 73$ \\
\hline
\end{tabular}


TABLE 4. (continued)

\begin{tabular}{|c|c|c|c|}
\hline$H(n)$ & $n$ & factorization of $n$ & seed \\
\hline \multirow[t]{2}{*}{187} & 407386980 & $2^{2} \cdot 3^{2} \cdot 5 \cdot 7^{2} \cdot 11 \cdot 13 \cdot 17 \cdot 19$ & $2^{2} \cdot 5 \cdot 7^{2} \cdot 19$ \\
\hline & 27726401736 & $2^{3} \cdot 3^{4} \cdot 11^{3} \cdot 17 \cdot 31 \cdot 61$ & $2^{3} \cdot 3^{4} \cdot 11^{3} \cdot 31 \cdot 61$ \\
\hline \multirow[t]{4}{*}{188} & 819131040 & $2^{5} \cdot 3^{2} \cdot 5 \cdot 7^{2} \cdot 13 \cdot 19 \cdot 47$ & $2^{5} \cdot 3^{2} \cdot 5 \cdot 7^{2} \cdot 13 \cdot 19$ \\
\hline & 2140041600 & $2^{7} \cdot 3^{3} \cdot 5^{2} \cdot 17 \cdot 31 \cdot 47$ & $2^{7} \cdot 3^{3} \cdot 5^{2} \cdot 17 \cdot 31$ \\
\hline & 21611457280 & $2^{8} \cdot 5 \cdot 7 \cdot 19 \cdot 37 \cdot 47 \cdot 73$ & $2^{8} \cdot 5 \cdot 7 \cdot 19 \cdot 37 \cdot 73$ \\
\hline & 479411093504 & $2^{14} \cdot 7 \cdot 19 \cdot 31 \cdot 47 \cdot 151$ & $2^{14} \cdot 7 \cdot 19 \cdot 31 \cdot 151$ \\
\hline \multirow[t]{4}{*}{189} & 623397600 & $2^{5} \cdot 3^{3} \cdot 5^{2} \cdot 7^{2} \cdot 19 \cdot 31$ & $2^{5} \cdot 5^{2} \cdot 7^{2} \cdot 19 \cdot 31$ \\
\hline & ${ }^{*} 675347400$ & $2^{3} \cdot 3^{2} \cdot 5^{2} \cdot 7^{2} \cdot 13 \cdot 19 \cdot 31$ & $2^{3} \cdot 5^{2} \cdot 31$ \\
\hline & ${ }^{*} 995248800$ & $2^{5} \cdot 3^{2} \cdot 5^{2} \cdot 7^{3} \cdot 13 \cdot 31$ & $2^{5} \cdot 5^{2} \cdot 7^{3} \cdot 31$ \\
\hline & ${ }^{*} 787936017383424$ & $2^{18} \cdot 3^{2} \cdot 7^{2} \cdot 13 \cdot 524287$ & $2^{18} \cdot 524287$ \\
\hline \multirow[t]{4}{*}{191} & 3328809120 & $2^{5} \cdot 3^{2} \cdot 5 \cdot 7^{2} \cdot 13 \cdot 19 \cdot 191$ & $2^{5} \cdot 3^{2} \cdot 5 \cdot 7^{2} \cdot 13 \cdot 19$ \\
\hline & 8696764800 & $2^{7} \cdot 3^{3} \cdot 5^{2} \cdot 17 \cdot 31 \cdot 191$ & $2^{7} \cdot 3^{3} \cdot 5^{2} \cdot 17 \cdot 31$ \\
\hline & 87825283840 & $2^{8} \cdot 5 \cdot 7 \cdot 19 \cdot 37 \cdot 73 \cdot 191$ & $2^{8} \cdot 5 \cdot 7 \cdot 19 \cdot 37 \cdot 73$ \\
\hline & 1948245082112 & $2^{14} \cdot 7 \cdot 19 \cdot 31 \cdot 151 \cdot 191$ & $2^{14} \cdot 7 \cdot 19 \cdot 31 \cdot 151$ \\
\hline 192 & 57575890944 & $2^{13} \cdot 3^{2} \cdot 11 \cdot 13 \cdot 43 \cdot 127$ & seed \\
\hline \multirow[t]{3}{*}{193} & 108061356200 & $2^{3} \cdot 5^{2} \cdot 7^{2} \cdot 19 \cdot 31 \cdot 97 \cdot 193$ & $2^{3} \cdot 5^{2} \cdot 31$ \\
\hline & 159248314400 & $2^{5} \cdot 5^{2} \cdot 7^{3} \cdot 31 \cdot 97 \cdot 193$ & $2^{5} \cdot 5^{2} \cdot 7^{3} \cdot 31$ \\
\hline & $12 \cdots 7277222912$ & $2^{18} \cdot 7^{2} \cdot 97 \cdot 193 \cdot 524287$ & $2^{18} \cdot 524287$ \\
\hline \multirow[t]{3}{*}{195} & 900463200 & $2^{5} \cdot 3 \cdot 5^{2} \cdot 7^{2} \cdot 13 \cdot 19 \cdot 31$ & $2^{5} \cdot 5^{2} \cdot 7^{2} \cdot 19 \cdot 31$ \\
\hline & 3221356320 & $2^{5} \cdot 3^{2} \cdot 5 \cdot 7 \cdot 13^{2} \cdot 31 \cdot 61$ & $2^{5} \cdot 3^{2} \cdot 7 \cdot 13^{2} \cdot 31 \cdot 61$ \\
\hline & 8628633000 & $2^{3} \cdot 3^{3} \cdot 5^{3} \cdot 13^{2} \cdot 31 \cdot 61$ & seed \\
\hline \multirow[t]{2}{*}{197} & 4720896180 & $2^{2} \cdot 3^{2} \cdot 5 \cdot 7^{2} \cdot 11 \cdot 13 \cdot 19 \cdot 197$ & $2^{2} \cdot 5 \cdot 7^{2} \cdot 19$ \\
\hline & 321300067176 & $2^{3} \cdot 3^{4} \cdot 11^{3} \cdot 31 \cdot 61 \cdot 197$ & $2^{3} \cdot 3^{4} \cdot 11^{3} \cdot 31 \cdot 61$ \\
\hline 198 & ${ }^{*} 22385029489560$ & $2^{3} \cdot 3^{10} \cdot 5 \cdot 23 \cdot 107 \cdot 3851$ & seed \\
\hline 200 & ${ }^{*} 714954240$ & $2^{9} \cdot 3^{2} \cdot 5 \cdot 7 \cdot 11 \cdot 13 \cdot 31$ & $2^{9} \cdot 3^{2} \cdot 7 \cdot 11 \cdot 13 \cdot 31$ \\
\hline 201 & 2481357060 & $2^{2} \cdot 3^{2} \cdot 5 \cdot 7^{2} \cdot 13 \cdot 17 \cdot 19 \cdot 67$ & $2^{2} \cdot 5 \cdot 7^{2} \cdot 19$ \\
\hline 202 & 3740553180 & $2^{2} \cdot 3^{2} \cdot 5 \cdot 7^{2} \cdot 13 \cdot 17 \cdot 19 \cdot 101$ & $2^{2} \cdot 5 \cdot 7^{2} \cdot 19$ \\
\hline \multirow[t]{2}{*}{203} & 2008725600 & $2^{5} \cdot 3 \cdot 5^{2} \cdot 7^{2} \cdot 19 \cdot 29 \cdot 31$ & $2^{5} \cdot 5^{2} \cdot 7^{2} \cdot 19 \cdot 31$ \\
\hline & 2369162250 & $2 \cdot 3^{3} \cdot 5^{3} \cdot 7^{2} \cdot 13 \cdot 19 \cdot 29$ & $2 \cdot 3^{3} \cdot 5^{3} \cdot 7^{2} \cdot 13 \cdot 19$ \\
\hline 204 & 886402440 & $2^{3} \cdot 3^{4} \cdot 5 \cdot 7 \cdot 11^{2} \cdot 17 \cdot 19$ & $2^{3} \cdot 3^{4} \cdot 5 \cdot 7 \cdot 11^{2} \cdot 19$ \\
\hline \multirow[t]{2}{*}{205} & 2839922400 & $2^{5} \cdot 3 \cdot 5^{2} \cdot 7^{2} \cdot 19 \cdot 31 \cdot 41$ & $2^{5} \cdot 5^{2} \cdot 7^{2} \cdot 19 \cdot 31$ \\
\hline & 3349505250 & $2 \cdot 3^{3} \cdot 5^{3} \cdot 7^{2} \cdot 13 \cdot 19 \cdot 41$ & $2 \cdot 3^{3} \cdot 5^{3} \cdot 7^{2} \cdot 13 \cdot 19$ \\
\hline 207 & 1199250360 & $2^{3} \cdot 3^{4} \cdot 5 \cdot 7 \cdot 11^{2} \cdot 19 \cdot 23$ & $2^{3} \cdot 3^{4} \cdot 5 \cdot 7 \cdot 11^{2} \cdot 19$ \\
\hline 209 & 513513000 & $2^{3} \cdot 3^{3} \cdot 5^{3} \cdot 7 \cdot 11 \cdot 13 \cdot 19$ & $2^{3} \cdot 3^{3} \cdot 5^{3} \cdot 7 \cdot 13$ \\
\hline 211 & 24362612820 & $2^{2} \cdot 3^{2} \cdot 5 \cdot 7^{2} \cdot 13 \cdot 19 \cdot 53 \cdot 211$ & $2^{2} \cdot 5 \cdot 7^{2} \cdot 19$ \\
\hline 212 & 2763489960 & $2^{3} \cdot 3^{4} \cdot 5 \cdot 7 \cdot 11^{2} \cdot 19 \cdot 53$ & $2^{3} \cdot 3^{4} \cdot 5 \cdot 7 \cdot 11^{2} \cdot 19$ \\
\hline 213 & 3702033720 & $2^{3} \cdot 3^{4} \cdot 5 \cdot 7 \cdot 11^{2} \cdot 19 \cdot 71$ & $2^{3} \cdot 3^{4} \cdot 5 \cdot 7 \cdot 11^{2} \cdot 19$ \\
\hline 214 & 5579121240 & $2^{3} \cdot 3^{4} \cdot 5 \cdot 7 \cdot 11^{2} \cdot 19 \cdot 107$ & $2^{3} \cdot 3^{4} \cdot 5 \cdot 7 \cdot 11^{2} \cdot 19$ \\
\hline 215 & 1162161000 & $2^{3} \cdot 3^{3} \cdot 5^{3} \cdot 7 \cdot 11 \cdot 13 \cdot 43$ & $2^{3} \cdot 3^{3} \cdot 5^{3} \cdot 7 \cdot 13$ \\
\hline 216 & 43947421401888 & $2^{5} \cdot 3^{6} \cdot 23 \cdot 137 \cdot 547 \cdot 1093$ & seed \\
\hline 217 & 1179832600464 & $2^{4} \cdot 3 \cdot 7^{2} \cdot 19 \cdot 31^{2} \cdot 83 \cdot 331$ & seed \\
\hline 218 & 2945943000 & $2^{3} \cdot 3^{3} \cdot 5^{3} \cdot 7 \cdot 11 \cdot 13 \cdot 109$ & $2^{3} \cdot 3^{3} \cdot 5^{3} \cdot 7 \cdot 13$ \\
\hline
\end{tabular}


TABLE 4. (continued)

\begin{tabular}{|c|c|c|c|}
\hline$H(n)$ & $n$ & factorization of $n$ & seed \\
\hline 220 & 3831421440 & $2^{9} \cdot 3 \cdot 5 \cdot 7 \cdot 11^{2} \cdot 19 \cdot 31$ & $2^{9} \cdot 7 \cdot 11^{2} \cdot 19 \cdot 31$ \\
\hline 221 & 10952611488 & $2^{5} \cdot 3^{2} \cdot 7 \cdot 13^{2} \cdot 17 \cdot 31 \cdot 61$ & $2^{5} \cdot 3^{2} \cdot 7 \cdot 13^{2} \cdot 31 \cdot 61$ \\
\hline 222 & 1727271000 & $2^{3} \cdot 3^{3} \cdot 5^{3} \cdot 7 \cdot 13 \cdot 19 \cdot 37$ & $2^{3} \cdot 3^{3} \cdot 5^{3} \cdot 7 \cdot 13$ \\
\hline \multirow[t]{2}{*}{224} & 13073550336 & $2^{10} \cdot 3^{4} \cdot 7 \cdot 11 \cdot 23 \cdot 89$ & $2^{10} \cdot 3^{4} \cdot 11 \cdot 23 \cdot 89$ \\
\hline & *66433720320 & $2^{13} \cdot 3^{3} \cdot 5 \cdot 11 \cdot 43 \cdot 127$ & seed \\
\hline 226 & 5275179000 & $2^{3} \cdot 3^{3} \cdot 5^{3} \cdot 7 \cdot 13 \cdot 19 \cdot 113$ & $2^{3} \cdot 3^{3} \cdot 5^{3} \cdot 7 \cdot 13$ \\
\hline 227 & 10597041000 & $2^{3} \cdot 3^{3} \cdot 5^{3} \cdot 7 \cdot 13 \cdot 19 \cdot 227$ & $2^{3} \cdot 3^{3} \cdot 5^{3} \cdot 7 \cdot 13$ \\
\hline 228 & 2716826112 & $2^{9} \cdot 3^{2} \cdot 7 \cdot 11 \cdot 13 \cdot 19 \cdot 31$ & $2^{9} \cdot 3^{2} \cdot 7 \cdot 11 \cdot 13 \cdot 31$ \\
\hline 229 & 12941019000 & $2^{3} \cdot 3^{3} \cdot 5^{3} \cdot 7 \cdot 13 \cdot 23 \cdot 229$ & $2^{3} \cdot 3^{3} \cdot 5^{3} \cdot 7 \cdot 13$ \\
\hline 230 & *3288789504 & $2^{9} \cdot 3^{2} \cdot 7 \cdot 11 \cdot 13 \cdot 23 \cdot 31$ & $2^{9} \cdot 3^{2} \cdot 7 \cdot 11 \cdot 13 \cdot 31$ \\
\hline 232 & 4146734592 & $2^{9} \cdot 3^{2} \cdot 7 \cdot 11 \cdot 13 \cdot 29 \cdot 31$ & $2^{9} \cdot 3^{2} \cdot 7 \cdot 11 \cdot 13 \cdot 31$ \\
\hline 233 & 150115204512 & $2^{5} \cdot 3^{2} \cdot 7 \cdot 13^{2} \cdot 31 \cdot 61 \cdot 233$ & $2^{5} \cdot 3^{2} \cdot 7 \cdot 13^{2} \cdot 31 \cdot 61$ \\
\hline 235 & ${ }^{*} 6720569856$ & $2^{9} \cdot 3^{2} \cdot 7 \cdot 11 \cdot 13 \cdot 31 \cdot 47$ & $2^{9} \cdot 3^{2} \cdot 7 \cdot 11 \cdot 13 \cdot 31$ \\
\hline 236 & 8436460032 & $2^{9} \cdot 3^{2} \cdot 7 \cdot 11 \cdot 13 \cdot 31 \cdot 59$ & $2^{9} \cdot 3^{2} \cdot 7 \cdot 11 \cdot 13 \cdot 31$ \\
\hline 237 & 11296276992 & $2^{9} \cdot 3^{2} \cdot 7 \cdot 11 \cdot 13 \cdot 31 \cdot 79$ & $2^{9} \cdot 3^{2} \cdot 7 \cdot 11 \cdot 13 \cdot 31$ \\
\hline 239 & 34174812672 & $2^{9} \cdot 3^{2} \cdot 7 \cdot 11 \cdot 13 \cdot 31 \cdot 239$ & $2^{9} \cdot 3^{2} \cdot 7 \cdot 11 \cdot 13 \cdot 31$ \\
\hline \multirow[t]{3}{*}{240} & 1307124000 & $2^{5} \cdot 3^{3} \cdot 5^{3} \cdot 7^{2} \cdot 13 \cdot 19$ & seed \\
\hline & 1381161600 & $2^{7} \cdot 3^{2} \cdot 5^{2} \cdot 7 \cdot 13 \cdot 17 \cdot 31$ & seed \\
\hline & 153003540480 & $2^{14} \cdot 3 \cdot 5 \cdot 7 \cdot 19 \cdot 31 \cdot 151$ & $2^{14} \cdot 7 \cdot 19 \cdot 31 \cdot 151$ \\
\hline 241 & 2096328767456 & $2^{5} \cdot 7^{2} \cdot 11^{2} \cdot 19^{2} \cdot 127 \cdot 241$ & $2^{5} \cdot 7^{2} \cdot 11^{2} \cdot 19^{2} \cdot 127$ \\
\hline \multirow[t]{2}{*}{245} & 3622293071600 & $2^{4} \cdot 5^{2} \cdot 7^{3} \cdot 31^{2} \cdot 83 \cdot 331$ & seed \\
\hline & 22047495446340 & $2^{2} \cdot 3^{3} \cdot 5 \cdot 7^{4} \cdot 13 \cdot 467 \cdot 2801$ & $2^{2} \cdot 3^{3} \cdot 7^{4} \cdot 13 \cdot 467 \cdot 2801$ \\
\hline 248 & 57897151488 & $2^{10} \cdot 3^{4} \cdot 11 \cdot 23 \cdot 31 \cdot 89$ & $2^{10} \cdot 3^{4} \cdot 11 \cdot 23 \cdot 89$ \\
\hline \multirow[t]{2}{*}{252} & *1553357978368 & $2^{8} \cdot 7^{2} \cdot 19^{2} \cdot 37 \cdot 73 \cdot 127$ & seed \\
\hline & *54934276752360 & $2^{3} \cdot 3^{6} \cdot 5 \cdot 23 \cdot 137 \cdot 547 \cdot 1093$ & seed \\
\hline 253 & 17624538624 & $2^{9} \cdot 3 \cdot 7 \cdot 11^{2} \cdot 19 \cdot 23 \cdot 31$ & $2^{9} \cdot 7 \cdot 11^{2} \cdot 19 \cdot 31$ \\
\hline 254 & 237191556096 & $2^{10} \cdot 3^{4} \cdot 11 \cdot 23 \cdot 89 \cdot 127$ & $2^{10} \cdot 3^{4} \cdot 11 \cdot 23 \cdot 89$ \\
\hline 255 & 2777638500 & $2^{2} \cdot 3^{3} \cdot 5^{3} \cdot 7^{2} \cdot 13 \cdot 17 \cdot 19$ & $2^{2} \cdot 5^{3} \cdot 7^{2} \cdot 13 \cdot 19$ \\
\hline 256 & 19209881600 & $2^{11} \cdot 5^{2} \cdot 7^{2} \cdot 13 \cdot 19 \cdot 31$ & seed \\
\hline 258 & 32950224384 & $2^{9} \cdot 3 \cdot 7 \cdot 11^{2} \cdot 19 \cdot 31 \cdot 43$ & $2^{9} \cdot 7 \cdot 11^{2} \cdot 19 \cdot 31$ \\
\hline 260 & 2144862720 & $2^{9} \cdot 3^{3} \cdot 5 \cdot 7 \cdot 11 \cdot 13 \cdot 31$ & $2^{9} \cdot 3^{3} \cdot 11 \cdot 31$ \\
\hline 261 & 4738324500 & $2^{2} \cdot 3^{3} \cdot 5^{3} \cdot 7^{2} \cdot 13 \cdot 19 \cdot 29$ & $2^{2} \cdot 5^{3} \cdot 7^{2} \cdot 13 \cdot 19$ \\
\hline 262 & 100383241728 & $2^{9} \cdot 3 \cdot 7 \cdot 11^{2} \cdot 19 \cdot 31 \cdot 131$ & $2^{9} \cdot 7 \cdot 11^{2} \cdot 19 \cdot 31$ \\
\hline 263 & 201532767744 & $2^{9} \cdot 3 \cdot 7 \cdot 11^{2} \cdot 19 \cdot 31 \cdot 263$ & $2^{9} \cdot 7 \cdot 11^{2} \cdot 19 \cdot 31$ \\
\hline \multirow[t]{3}{*}{264} & 15174001920 & $2^{8} \cdot 3 \cdot 5 \cdot 7 \cdot 11 \cdot 19 \cdot 37 \cdot 73$ & $2^{8} \cdot 5 \cdot 7 \cdot 19 \cdot 37 \cdot 73$ \\
\hline & *43861478400 & $2^{10} \cdot 3^{3} \cdot 5^{2} \cdot 23 \cdot 31 \cdot 89$ & seed \\
\hline & 336607789056 & $2^{14} \cdot 3 \cdot 7 \cdot 11 \cdot 19 \cdot 31 \cdot 151$ & $2^{14} \cdot 7 \cdot 19 \cdot 31 \cdot 151$ \\
\hline 265 & 8659696500 & $2^{2} \cdot 3^{3} \cdot 5^{3} \cdot 7^{2} \cdot 13 \cdot 19 \cdot 53$ & $2^{2} \cdot 5^{3} \cdot 7^{2} \cdot 13 \cdot 19$ \\
\hline 266 & 3134799360 & $2^{9} \cdot 3^{3} \cdot 5 \cdot 7 \cdot 11 \cdot 19 \cdot 31$ & $2^{9} \cdot 3^{3} \cdot 11 \cdot 31$ \\
\hline 267 & 14541754500 & $2^{2} \cdot 3^{3} \cdot 5^{3} \cdot 7^{2} \cdot 13 \cdot 19 \cdot 89$ & $2^{2} \cdot 5^{3} \cdot 7^{2} \cdot 13 \cdot 19$ \\
\hline 269 & 43952044500 & $2^{2} \cdot 3^{3} \cdot 5^{3} \cdot 7^{2} \cdot 13 \cdot 19 \cdot 269$ & $2^{2} \cdot 5^{3} \cdot 7^{2} \cdot 13 \cdot 19$ \\
\hline 270 & ${ }^{*} 2701389600$ & $2^{5} \cdot 3^{2} \cdot 5^{2} \cdot 7^{2} \cdot 13 \cdot 19 \cdot 31$ & $2^{5} \cdot 5^{2} \cdot 7^{2} \cdot 19 \cdot 31$ \\
\hline
\end{tabular}


TABLE 4. (continued)

\begin{tabular}{|c|c|c|c|}
\hline$H(n)$ & $n$ & factorization of $n$ & seed \\
\hline & $* 71271827200$ & $2^{8} \cdot 5^{2} \cdot 7 \cdot 19 \cdot 31 \cdot 37 \cdot 73$ & seed \\
\hline \multirow[t]{2}{*}{272} & 23450730240 & $2^{8} \cdot 3 \cdot 5 \cdot 7 \cdot 17 \cdot 19 \cdot 37 \cdot 73$ & $2^{8} \cdot 5 \cdot 7 \cdot 19 \cdot 37 \cdot 73$ \\
\hline & 520212037632 & $2^{14} \cdot 3 \cdot 7 \cdot 17 \cdot 19 \cdot 31 \cdot 151$ & $2^{14} \cdot 7 \cdot 19 \cdot 31 \cdot 151$ \\
\hline 273 & 57648181500 & $2^{2} \cdot 3^{2} \cdot 5^{3} \cdot 7^{3} \cdot 13^{3} \cdot 17$ & seed \\
\hline 275 & 31638321000 & $2^{3} \cdot 3^{2} \cdot 5^{3} \cdot 11 \cdot 13^{2} \cdot 31 \cdot 61$ & $2^{3} \cdot 3^{2} \cdot 5^{3} \cdot 13^{2} \cdot 31 \cdot 61$ \\
\hline \multirow[t]{2}{*}{276} & 31727458560 & $2^{8} \cdot 3 \cdot 5 \cdot 7 \cdot 19 \cdot 23 \cdot 37 \cdot 73$ & $2^{8} \cdot 5 \cdot 7 \cdot 19 \cdot 37 \cdot 73$ \\
\hline & 703816286208 & $2^{14} \cdot 3 \cdot 7 \cdot 19 \cdot 23 \cdot 31 \cdot 151$ & $2^{14} \cdot 7 \cdot 19 \cdot 31 \cdot 151$ \\
\hline 277 & 888988066400 & $2^{5} \cdot 5^{2} \cdot 7^{2} \cdot 19 \cdot 31 \cdot 139 \cdot 277$ & $2^{5} \cdot 5^{2} \cdot 7^{2} \cdot 19 \cdot 31$ \\
\hline 278 & 22933532160 & $2^{9} \cdot 3^{3} \cdot 5 \cdot 7 \cdot 11 \cdot 31 \cdot 139$ & $2^{9} \cdot 3^{3} \cdot 11 \cdot 31$ \\
\hline \multirow[t]{2}{*}{279} & ${ }^{*} 42763096320$ & $2^{8} \cdot 3 \cdot 5 \cdot 7 \cdot 19 \cdot 31 \cdot 37 \cdot 73$ & $2^{8} \cdot 5 \cdot 7 \cdot 19 \cdot 37 \cdot 73$ \\
\hline & 997978703400 & $2^{3} \cdot 3^{3} \cdot 5^{2} \cdot 7 \cdot 31^{2} \cdot 83 \cdot 331$ & seed \\
\hline \multirow[t]{2}{*}{282} & 64834371840 & $2^{8} \cdot 3 \cdot 5 \cdot 7 \cdot 19 \cdot 37 \cdot 47 \cdot 73$ & $2^{8} \cdot 5 \cdot 7 \cdot 19 \cdot 37 \cdot 73$ \\
\hline & 1438233280512 & $2^{14} \cdot 3 \cdot 7 \cdot 19 \cdot 31 \cdot 47 \cdot 151$ & $2^{14} \cdot 7 \cdot 19 \cdot 31 \cdot 151$ \\
\hline \multirow[t]{2}{*}{284} & 97941285120 & $2^{8} \cdot 3 \cdot 5 \cdot 7 \cdot 19 \cdot 37 \cdot 71 \cdot 73$ & $2^{8} \cdot 5 \cdot 7 \cdot 19 \cdot 37 \cdot 73$ \\
\hline & 2172650274816 & $2^{14} \cdot 3 \cdot 7 \cdot 19 \cdot 31 \cdot 71 \cdot 151$ & $2^{14} \cdot 7 \cdot 19 \cdot 31 \cdot 151$ \\
\hline \multirow[t]{4}{*}{285} & 42054536160 & $2^{5} \cdot 3^{2} \cdot 5 \cdot 7^{2} \cdot 13 \cdot 19^{2} \cdot 127$ & $2^{5} \cdot 3^{2} \cdot 7^{2} \cdot 13 \cdot 19^{2} \cdot 127$ \\
\hline & 54648009000 & $2^{3} \cdot 3^{2} \cdot 5^{3} \cdot 13^{2} \cdot 19 \cdot 31 \cdot 61$ & $2^{3} \cdot 3^{2} \cdot 5^{3} \cdot 13^{2} \cdot 31 \cdot 61$ \\
\hline & ${ }^{*} 1109541413120$ & $2^{8} \cdot 5 \cdot 7 \cdot 19^{2} \cdot 37 \cdot 73 \cdot 127$ & $2^{8} \cdot 7 \cdot 19^{2} \cdot 37 \cdot 73 \cdot 127$ \\
\hline & ${ }^{*} 24613169545216$ & $2^{14} \cdot 7 \cdot 19^{2} \cdot 31 \cdot 127 \cdot 151$ & seed \\
\hline 287 & 180789462659988 & $2^{2} \cdot 3^{3} \cdot 7^{4} \cdot 13 \cdot 41 \cdot 467 \cdot 2801$ & $2^{2} \cdot 3^{3} \cdot 7^{4} \cdot 13 \cdot 467 \cdot 2801$ \\
\hline 290 & 83410119000 & $2^{3} \cdot 3^{2} \cdot 5^{3} \cdot 13^{2} \cdot 29 \cdot 31 \cdot 61$ & $2^{3} \cdot 3^{2} \cdot 5^{3} \cdot 13^{2} \cdot 31 \cdot 61$ \\
\hline 291 & 427721411658996 & $2^{2} \cdot 3^{3} \cdot 7^{4} \cdot 13 \cdot 97 \cdot 467 \cdot 2801$ & $2^{2} \cdot 3^{3} \cdot 7^{4} \cdot 13 \cdot 467 \cdot 2801$ \\
\hline 293 & 1291983233155524 & $2^{2} \cdot 3^{3} \cdot 7^{4} \cdot 13 \cdot 293 \cdot 467 \cdot 2801$ & $2^{2} \cdot 3^{3} \cdot 7^{4} \cdot 13 \cdot 467 \cdot 2801$ \\
\hline 295 & 169696449000 & $2^{3} \cdot 3^{2} \cdot 5^{3} \cdot 13^{2} \cdot 31 \cdot 59 \cdot 61$ & $2^{3} \cdot 3^{2} \cdot 5^{3} \cdot 13^{2} \cdot 31 \cdot 61$ \\
\hline 296 & 16569653760 & $2^{9} \cdot 3^{3} \cdot 5 \cdot 11 \cdot 19 \cdot 31 \cdot 37$ & $2^{9} \cdot 3^{3} \cdot 11 \cdot 31$ \\
\hline 297 & *125356165141536 & $2^{5} \cdot 3^{10} \cdot 7 \cdot 23 \cdot 107 \cdot 3851$ & seed \\
\hline 298 & 428555439000 & $2^{3} \cdot 3^{2} \cdot 5^{3} \cdot 13^{2} \cdot 31 \cdot 61 \cdot 149$ & $2^{3} \cdot 3^{2} \cdot 5^{3} \cdot 13^{2} \cdot 31 \cdot 61$ \\
\hline 299 & 9866368512 & $2^{9} \cdot 3^{3} \cdot 7 \cdot 11 \cdot 13 \cdot 23 \cdot 31$ & $2^{9} \cdot 3^{3} \cdot 11 \cdot 31$ \\
\hline
\end{tabular}

\section{ACKNOWLEDGMENTS}

We would like to thank Professor Masanobu Kaneko for introducing us to this topic. We are also grateful to the referee for his/her useful advice.

\section{REFERENCES}

[1] D. Callan, Solution to Problem 6616, Amer. Math. Monthly 99 (1992), 783-789.

[2] G. L. Cohen, Numbers whose positive divisors have small integral harmonic mean, Math. Comp. 66 (1997), 883-891. MR 97f:11007.

[3] G. L. Cohen and R. M. Sorli, Harmonic seeds, Fibonacci Quart. 36 (1998), 386-390; Errata, Fibonacci Quart. 39 (2001), 4. MR 99j:11002

[4] G. L. Cohen and Deng Moujie, On a generalisation of Ore's harmonic numbers, Nieuw. Arch. Wisk. (4) 16 (1998), 161-172. MR 2000k:11008 
[5] M. Garcia, On numbers with integral harmonic mean, Amer. Math. Monthly 61 (1954), 89-96. MR 15:506d

[6] R. K. Guy, Unsolved Problems in Number Theory, second edition, Springer-Verlag, New York, 1994. MR 96e:11002

[7] H. J. Kanold, Über das harmonische Mittel der Teiler einer natürlichen Zahl, Math. Ann. 133 (1957), 371-374. MR 19:635f

[8] O. Ore, On the averages of the divisors of a number, Amer. Math. Monthly 55 (1948), 615-619. MR 10:284a

[9] Solution to Problem E3445, Amer. Math. Monthly 99 (1992), 795.

[10] C. Pomerance, On a problem of Ore: Harmonic numbers (unpublished typescript); see Abstract 709-A5, Notices Amer. Math. Soc. 20 (1973) A-648.

Graduate School of Mathematics, Kyushu University 33, Fukuoka 812-8581, Japan

E-mail address: tgoto@math.kyushu-u.ac.jp

Current address: Department of Mathematics, Tokyo University of Science, Noda, Chiba 2788510, Japan

E-mail address: goto_takeshi@ma.noda.tus.ac.jp

Faculty of Mathematics, Kyushu University 33, Fukuoka 812-8581, Japan

E-mail address: ma200019@math.kyushu-u.ac.jp 